\title{
Adult autonomy and specific-purpose phonetics
}

\section{Martin Walton}

\section{OpenEdition}

\section{Journals}

Electronic version

URL: http://journals.openedition.org/asp/4307

DOI: $10.4000 / a s p .4307$

ISSN: 2108-6354

\section{Publisher}

Groupe d'étude et de recherche en anglais de spécialité

\section{Printed version}

Date of publication: 1 October 1993

Number of pages: $285-310$

ISSN: $1246-8185$

\section{Electronic reference}

Martin Walton, «Adult autonomy and specific-purpose phonetics », ASp [Online], $2 \mid$ 1993, Online since 05 March 2014, connection on 19 April 2019. URL : http://journals.openedition.org/asp/4307 ; DOI 10.4000/asp.4307

This text was automatically generated on 19 April 2019

Tous droits réservés 


\title{
Adult autonomy and specific-purpose phonetics
}

\author{
Martin Walton
}

\section{Introduction}

1 Any reflection on the precise role of autonomous learning in the second language learning process is likely to be both paradoxical and provocative. For in attempting to establish, however tentatively, what a second language learner, say of English in France, can do autonomously, or to decide how this can be done, may mean appearing to make decisions which belong to the learner and which will vary from learner to learner. It will also require taking a look at the role of the second language teacher, native or nonnative, who may or may not support any or all of our general or particular conclusions about any given learner or about any given item to be learned.

2 Autonomy is however a priority problem facing teachers today, not only in terms of learner-centred teaching but in terms of making learning time most effective (given the limited number of hours of teacher presence) and of making the greatest economic use of the resources available and of individual learner free or non-collective time.

3 A native teacher like myself will have to be conscious of the particular role expected of him by both the institutional authorities and the learners concerned, and to a great extent, we cannot identify what autonomous learning can or could be without determining what our roles as teachers can or could be. No matter how conscious we may be of the limitations of our own teaching and learning models, the solutions we provide will necessarily be based mainly on our own limited theory and teaching experience.

4 It is thus on such a tentative and very limited theoretical level, that I propose the following reflection on autonomy in general, using a brief analysis of my D.E.A. bibliographical research on the work of Maria Montessori, a pioneer in scientific pedagogy, and, related to her particular concept of autonomy, a few propositions for 
autonomous learning of English pronunciation for French learners which I have been exploring with my own, largely adult, students.

5 Apart from general reading on the subject, such as Saussure's account of phonological principles in his Cours de linguistique générale, some essays by Jacobson, Troubetskoy and Martinet, and my use of coursebooks like English Phonetics and Phonology by Peter Roach (1991) or Michel Ginesy's Exercices de phonétique anglaise (1989), my personal knowledge of phonetics should not be considered sufficient to be embarking on any worthwhile 'internal' commentary.

\section{Montessori - a definition of autonomous learning}

In choosing to study the work of Maria Montessori, I had hoped to find there a source of teaching strategy for first language learning which might be useful, either directly or indirectly, to contrast with my own experience of child and adult learners of English in France. I had been looking for a sounding-board for reflection on child learning and a possible source of innovation in my own teaching practice. I had not expected to find that the autonomous elements in her teaching lay at the very core of her approach.

7 To a great extent, Montessori's autonomy principles went hand in hand with a philosophical and social vision of the child which challenged the traditional or institutional vision of the day; that of an anarchic, helpless and dependent being threatening the rational and ordered world of the adult. Montessori sought from the start to combat such a vision and to develop the materials which would liberate the child learner from the all-powerful adult even at a very early age. Her materials were thus based on a language corresponding to the physical and mental development of the particular child. It might be tactile, visual, graphic or verbal, but it was always related to the needs and interests of a particular age group observed over a period of a lifetime, that of a qualified psychiatrist, an experienced child psychologist, the first ever Italian woman doctor in her day.

8 It was also based on a radical belief in the profoundly rational and strictly logical structure and thought processes of the child - which was, in itself, a break with the 19th century Romantic view of child thinking as predominantly anarchic, emotive and irrational. This view of child thinking and learning strategy as having a purely rational rather than irrational basis remains a controversial one and many teachers might query its possible applications with regard to adult teaching. My own personal experience would lead me to support the Montessori view, but taking, however, social and aesthetic elements into greater account. It would lead me to consider that while adults do not seem to show exactly the same blind logic, (the almost tedious rationality of the very early learner), there is nonetheless a similar rationale imposing itself but this time expressing itself more in L1 terms. While I would not suggest that contrastive transfer is the single mechanism regulating adult second-language learning, I do see that particular phenomenon as a possible mechanism to exploit, one of many, and not one to reject or bury under some cultural brain-storming or avalanche of L2 injections, a philosophy often preached by parents and teachers alike - the old "you have to go and live in the country" dogma or, "if I keep talking to you in English you will start doing exactly the same thing" syndrome. 


\section{The role of the teacher}

9 The role of the teacher in the Montessori view was to provide the material which addressed itself directly to the learner, appealing to his or her own inner logic, in a language that only he or she could really understand. These pedagogical tools were developed after a long period of trial and error during which the teacher observed the needs and performances of the particular learner or learner group, and then adapted the materials appropriately in order to provide fully autonomous learning.

Thus, teaching was never to act for the learner, nor to demonstrate a particular skill to the learner and expect an automatic mimetic response. The teacher only provided the learner with an environment or learning task which, in itself, was an opportunity for the learner to exercise a skill which was already latent within him. The materials were not self-teaching in the sense that they did not replace the teacher. They were not teach yourself methods, like so many of these teach yourself language methods available on the market. They were self-learning in the sense that they allowed learners to discover their own latent skills, drawing on inner motivations and needs related to the physiological and psychological development of the particular age group. The materials made use of previously acquired skills and anticipated the learner's inner developmental project whether this was to learn how to dress him or herself and work with attaching very difficult buttons, or to learn how to write and work with engravings at the age of two and a half or three.

11 This view of learning as, potentially, a totally autonomous activity (given the right materials of course) was and is a challenge to the traditionally active teacher. In sharp conflict with the teacher who sought to act for the learner, this new role was to find ways for the learner to act. The distinction between what the learner could do himself and what he could not yet do, as against what the teacher was already capable of doing, was one which would prevent all useless activity and much failure on the part of the learner.

Tout ce qui est aide inutile constitue une entrave au développement des forces naturelles. (Montessori 1958a: 44)

It was also in conflict with a view that did not encourage the kind of inevitable error that occurs when the learner is allowed complete freedom to exercise the skills being acquired and to discover how to correct himself. The Montessori view of error was not that of an occasion to correct the learner. It was an occasion to assess the learner's needs, to plan future teaching programmes, to assess the materials being used to learn the particular skill, and to modify the language of the material in order to avoid failure. The teacher's job was not to demonstrate his or her own capacities directly to the incompetent learner, to one who had not yet fully acquired a particular skill. Nor to punish or reward the learner. It was to transfer those capacities in a way which the learner could readily understand and which appealed to the learner's own inner developmental logic and which was in itself a pleasure and a reward. It was also to identify for the learner what he or she had already acquired or had just successfully learned.

In Chart 1, I have very crudely resumed, in "do and don't" fashion, the portrait of the ideal (parent or) teacher as gleaned from a survey of Montessori's works which are listed in the bibliography at the end for those interested in learning about her methods in more detail. 
(1) from the very start, the foundation of any scientific pedagogy/androgogy. In other words, it is not really child teaching for children, in the usual sense of the term, but in fact adult teaching or teaching children how to become adult in the true sense of the word. Indeed, we might say that it is simply person-teaching. This is in many ways what makes it so interesting as a schema for assessing the creation of both child and adult materials and observing and exploiting learning strategies. In short, in some ways, it is an ideal programme for our ideal centre de resources linguistiques to carry out research with.

Chart 1. A resumé of the Montessori schema for authentic autonomous learning

\begin{tabular}{|c|c|}
\hline What the teacher's role is NOT & What the teacher's role IS \\
\hline $\begin{array}{l}\text { Substituting for or demonstrating to } \\
\text { the learner }\end{array}$ & Preparing the learning environment \\
\hline $\begin{array}{l}\text { Making choices of activities for the } \\
\text { learner }\end{array}$ & $\begin{array}{l}\text { Creating materials and learning tools appropriate for } \\
\text { the learning stage }\end{array}$ \\
\hline $\begin{array}{l}\text { Regulating frequency and duration of } \\
\text { any activity }\end{array}$ & $\begin{array}{l}\text { Allowing the learner to work at his/her own tempo/ } \\
\text { rhythm, free to repeat the task any number of times }\end{array}$ \\
\hline Providing the theory & $\begin{array}{l}\text { Observing the learner's independent deduction of } \\
\text { cognate principles }\end{array}$ \\
\hline $\begin{array}{l}\text { Eliciting theory directly from the } \\
\text { learner }\end{array}$ & Allowing the learner to enunciate the theory \\
\hline $\begin{array}{l}\text { Immobilising the learner, making } \\
\text { them passive }\end{array}$ & $\begin{array}{l}\text { Encouraging the use of movement in different physical } \\
\text { spatial environments. Encouraging initiative }\end{array}$ \\
\hline $\begin{array}{l}\text { Correcting the learner's errors } \\
\text { explicitly }\end{array}$ & $\begin{array}{l}\text { Providing auto-corrective tools which avoid error or the } \\
\text { need for correction. }\end{array}$ \\
\hline Assessing the learner & $\begin{array}{l}\text { Allowing him to assess himself on materials that } \\
\text { sharpen his senses }\end{array}$ \\
\hline
\end{tabular}




\begin{tabular}{|l|l|}
\hline Rewarding the learner. & $\begin{array}{l}\text { The material will allow the learner to enjoy exercising } \\
\text { his skills and eliminating his errors. }\end{array}$ \\
\hline Punishing the learner & $\begin{array}{l}\text { Providing materials that allow the learner to achieve a } \\
\text { certain accuracy and avoid humiliation }\end{array}$ \\
\hline $\begin{array}{l}\text { Providing the same material for } \\
\text { different learners at the same time }\end{array}$ & $\begin{array}{l}\text { Only one sample of any material or task at any one time. } \\
\text { Learners do different work and take turns to use each } \\
\text { task which they freely choose during class }\end{array}$ \\
\hline $\begin{array}{l}\text { Interrupting the learner during his } \\
\text { activity or task in order to correct or } \\
\text { direct or explain }\end{array}$ & $\begin{array}{l}\text { Providing engaging tasks/tools. Responding only to } \\
\text { precise learner-questions and briefly }\end{array}$ \\
\hline
\end{tabular}

\section{Some of the problems with adult autonomy}

17 Several obvious differences emerge, however, between adult and child learners even within any such authentically autonomous framework. Unlike children, adult learners do not really need the same purely adult (or parental) presence of the teacher ensuring social harmony and individual physical safety and psychological security. (Or do they? So many of our adults have been so infantilised during their primary and secondary academic careers that some of them actually expect and respond well to a more authoritative or even authoritarian approach.)

Unlike children, adults do not show obvious physiological and psychological natural growth mechanisms working towards fixed (adult) models. (Or do they, in linguistic terms? How many adult learners have identified their long-term linguistic competence model for the second language in any realistic fashion? Yet another interrogative sociopsychological abyss for research.)

But above all, adult learners do expect that during the only too brief teacher presence time, communicative learning should take place directly between the teacher (who for them is often the model of competence) and themselves. So that while a certain amount of teacher self-limitation and more learner initiative with solo, or pair, or group activities will lead to learners acquiring greater independence in the long term (especially if the skills they acquire in class and the tools used are geared towards long-term learning, i.e. the realistic terms of learning a language), it would be provocative to seek to ignore the learners' institutional expectations.

Learning a second language for children and adults takes place over over at least a number of years of reasonably regular activity in the language rather than a certain number of hours - whether those be collective school hours (representing probably no more than 100 real hours of personal, communicative, and autonomously engaged linguistic activity during adolescence over 7 or 8 academic years) or modules of 20,40 , or 60 adult training hours. While child learners may have the time to construct for themselves over the years and make many of the inevitable errors necessary before they begin to start correcting themselves - adults will not, and can be saved from unnecessary error learning by far more complex explanations and through the understanding of 
concepts which few children would have either the patience or the ability to try and absorb.

It is also clear that in the ideal Montessori learning world, much of the teacher's task depends on the careful development of the materials. The degree to which Montessori puts faith in natural autonomous mechanisms remains a controversial though interesting one, even today, and remains an area of research close to the hearts of generative grammarians in the Chomskian tradition. Whether or not such mechanisms prove to exist in second-language adult learners, the individual teacher will be faced today with few or no materials immediately available that base themselves on any strictly autonomous learner-language. Thus, in seeking to observe any adult natural growth mechanisms intuited or to exploit these, teachers will often have to be experimental, which in adult teaching can be a risky and time-wasting business for both learners and teachers.

There is also the fact that when it comes to dealing with second-language learning adults (in contrast with first language child-learning), especially adults who have emerged from a French institutional education, which takes little of its inspiration from the autonomous joys of the Montessori model, it would be utopian if not irresponsible to expect the kind of active responsible learner well used to learning in this fashion from early childhood. We have to take into account the rather commoner model emerging from the present system, an adult who is very often passive and dependent, and one who expects the teacher to act for him and in front of him in order for any learning to take place.

There is also little point in giving the child or adult learner a vague measure of autonomy without the appropriate material, and the material we give ought equally to be assessed by the action of the learner, after the task.

Too often we see autonomy as free time to do what the teacher says we have to do, sometimes with very little material support to guarantee any success in the task. Too often, the learner is asked not to exercise an act of free learning, but one of tedious repetition simply to please his interrogator in the following torture session called examinations.

There can be total autonomy in the presence of the teacher who is observing and responding to questions which arise quite spontaneously from the selected learning activity. There can also be autonomy in the absence of the teacher, but in that case the learning tool might better be an auto-corrective one - if the teacher's role is not simply to be that of the professional corrector/demonstrator, he or she who can demonstrate his or her own capacities to show up the learner's failures when the results are being assessed later on.

26 Adult learners have in their minds fixed teacher models, just as teachers have ideal models in their minds, models of their ideal teacher and models of their ideal learner. In requiring that the teacher give the learner back his freedom, in encouraging an adult response from the child learner, the Montessori model still provides a challenge to many common or institutionalised models today, and even more so when used to assess the adult nature of adult teaching for adults and adult autonomous learning materials.

It seems to me that however idealistic or challenging many of the principles Montessori has constructed, a homeopathic dose of such authentic autonomy might do the world of good in our adult classes - especially as regards allowing: 1) choice of materials, 2) the observation of learner choices and decisions, and 3) assessment of materials in relation to 
stated objectives and not just, as is often the case, assessment of the learner's performance.

Such principles also challenge in particular the native teacher of English who may tend to confuse his own competence in the language, acquired in a native English-speaking environment, with the skills of the L2 learner who is trying to acquire the English language in, say, a French-speaking environment. It was in response to that challenge that I began thinking about the problems of making a learning skill such as English pronunciation a more independent activity and not just a matter of my direct teaching of pronunciation skills, drills and repetition, labwork, etc., descriptive and analytic activities making the learner basically dependent on myself or on the sound sources available.

\section{Summary of preliminary conclusions}

While the principles enunciated by the Montessori approach to child education i.e. learning based entirely on autonomy and quite dependent on the creation of purely learner-tool materials, are unlikely to offer any immediately practical support to the teacher who has to work not only with anti-autonomous materials but with learners who have had little or no experience of such utopian autonomous conditions (nor of any such andragogical as opposed to pedagogical principles being applied during class periods), the challenge provided by the Montessori philosophy may be worthwhile as a schema with which to measure the autonomous aspects of existing contemporary learning materials and as a guideline for the teacher to help to introduce some measure of learning autonomy during and outside of class time.

Consequently, while any teacher may rightly find such a challenge to be far too extreme and be unable to seriously entertain a vision whereby the learner, and especially the adult second language learner, becomes entirely independent in the brief course of a language learning module, he or she may consider it worthwhile to inject at the very least an experimental dose of learner choice and learner-based material requiring less or the very minimum of teacher-assistance.

The teacher may seek to attain a period of minimum overt teacher participation in order to be able to observe autonomous learning activity and thereafter provide better autonomous learning materials for the future.

This reflection in the course of my DEA studies was the background for my beginning to ask myself whether or not the principles Montessori used for the creation of her autonomous child-learning tasks might be useful to exploit for my French adult learners of English.

Could I focus on, or identify already-existing materials that gave my adult learner greater independence for the learning of English as a foreign language? Could I observe any natural autonomous mechanisms in my own adult second language learners and seek to exploit these? Was I clearly distinguishing my own particular skills and competence in English from my learners' needs and skills requiring to be taught? Could I provide materials that would make the learner less dependent on the teacher, native or nonnative, and enable them to achieve a certain measure of minimum autonomy? 


\section{Autonomy integrated into communication activities in class-teacher distance}

A measure of autonomy, I have found, is relatively easy to introduce as an alternative version of certain existing teacher-participation activities.

Where communication activities for learners are concerned, for example, we may identify, at least two distinct species of activity usually known as "pair work". One is where the teacher participates, making his or her listening presence and corrective presence felt, while the two learners perform a given communicative task. Indeed, strictly speaking, this first type is not pair work at all; it is a trio activity where the teacher is an active first violinist. The second type is where the teacher provides a directed or starting activity for two learners and observes from a discrete distance what happens without any direct interruption or felt presence on the part of the teacher. The benefits of "trio work", the first type, are substantial but very different from those of authentic or autonomous pair work. In trio work there is teacher activity as a speaker, or just as a listening observer, or both. In authentic autonomous pair work there may or may not be any overt possibility for observation, either due to the number of pairs or - the teacher may choose to adopt and maintain a certain distance in order not to disturb the autonomous communicative activity which the presence of the teacher can actually kill, thus preventing the learner from concentrating on the purely uncritical function of the language. In such pair work learners are often happy to efficiently transfer their knowledge from one to the other using their own native language, or using concepts which are rooted in either their own learner-level or their own social and cultural language - neither of which may correspond to the teacher's own level of thought or culture. While the teacher might be surprised by the over-simplicity of inductive theory enunciated by one learner to the other, learners can benefit by sharing and transfer without the corrective or institutional presence, which may always be called upon in the event of a query or uncertainty.

There are thus two forms of pair work, which we may call: trio-pair work (teacher participating or overtly observing) and autonomous-pair work (teacher absent or very distant from the communicative action). Not so easy is the task of providing solo or paired autonomous activity in order to get learners to acquire skills usually dependent on such teacher-participation, like pronunciation learning. This however was an area which I felt worth investigating.

The concluding section of this paper provides only a very brief résumé of my own experience in trying to explore this area. It happens to be one that interests me personally, and is particularly related to the role of the native teacher who is often given the task of performing the pronunciation miracle. Much of what I have determined so far is speculative and exploratory. I have chosen to indicate only the general outline of the task yet to be accomplished rather than any details of my own very early and relatively elementary observations, probably already well-known to any experienced theoretician or practicing teacher. 


\subsection{The dictionary as one autonomous learning tool introduced into class periods}

It was following reflection on the preparation of the autonomous environment principle that led me to introduce one copy of Robert-Collins dictionary (1991) for every two students in my classes and in the language lab at the IUT, in an attempt to provide, and observe the use of, at least one autonomous tool. Needless to say, it was necessary to break with the Montessori principle of providing only ONE copy of any tool (intended to develop harmonious social interchange in the group and to encourage learners to move around the learning space and observe others making use of each tool) since university students tended to remain completely immobile at their desks rather than get up in order to consult the dictionary in full view of the class. There was also the fact that in a fully authentic autonomous environment there would be enough different tools for each and every student not to have to share.

The effect of providing one copy between two (finance being limited) was intended to give students immediate access to solving individual lexical problems as they arose, without forcing the teacher to spend precious time on haphazard items which did not necessarily concern the other learners. In passing, I was able to observe that students were not familiar with such a practice, and did not show much initiative at the start in making use of the tool, until they had been encouraged, by specific purpose tasks, to avail of it. More relevant to the present discussion, none of the students were capable of using the pronunciation support in the dictionary. They had never looked at the phonemic guide and presumed that the phonetic indications for each word did not concern them.

Most students, when pronouncing any new word, simply used their previously acquired French orthographic pronunciation model to produce approximations and revealed a total ignorance of even the most elementary features of English pronunciation.

Even the suprasegmental symbols for word stress and long vowels seemed to be a novel element. Nor were they familiar with the schwa and /I/ sound-symbols, a fairly minimum competency when reading and correctly stressing English words.

42 The first observation only confirms what many third-level and adult teachers will no doubt have already noticed in their classes. Learners, even after many years of institutional language learning, will often fail to have acquired the familiarity got from regular recourse to a tool that can offer them a relative degree of lexical and morphological autonomy.

The second observation will be even less surprising, for although a phonetic support model is provided in much of the secondary school method literature, teachers rarely attribute it the priority or class time required for individual learners to acquire this skill. Even more rarely, it should be added, is that skill ever integrated into the evaluation system at the end of the term or year.

44 Even more worrying is that almost none of them will have come to view the dictionary as a pronunciation tool which, even for native English speakers, is indispensible. More often than not, learners are left to their own devices to make use of the dictionary, and in many cases, this may describe some odd pocket variety or ancient specimen unearthed from a perhaps dustless but very uninhabited corner of their own or grandparents' homes. 


\subsection{Teacher-competence versus learner-needs} skills while using phonetic pronunciation guides in class. It is whether for learners, such a tool cannot give greater autonomy, either to be able to check the pronunciation of previously-acquired vocabulary and to acquire new items more accurately! A skill which makes the learner more teacher-independent is one which equally liberates the teacher, if and when of course that skill has been fully appropriated by the learner to some reasonable degree of accuracy and absorbed into his or her learning strategy practice.

Perhaps another reason is for the failure to integrate this learning tool into Englishteaching practice is that teachers feel that the acquisition of such a skill could take up too much class time. This would be true that if learners were expected to follow a complete course in phonetics and phonology. But what I am proposing is to simplify our task by concentrating on at least two very minimum reading skills and objectives. 
51 I am, therefore, not proposing that all adult learners and university students be asked to learn how to transcribe phonetically in English or to be able to produce the correct phonetic transcription, given the usual orthographic spelling, even if these skills in themselves will prove to be highly worthwhile. Nor am I proposing that endless minimum pairs be contrasted in recognition and production drills, visually, auditively or orally. Nor am I seeking to justify or defend the science of phonetics, nor add to the inventory of its achievements

52 I am merely proposing a minimum specific objective, the acquisition of a minimum autonomous reading skill for any French learner of English, as follows:

53 - That when fully concentrated on obtaining the standard English (or American) pronunciation of a word, the learner be able to read reasonably accurately, the pronunciation guide in the dictionary he or she is using, in other words, be able to make use of the phonetic symbols in order to read the standard pronunciation of a series of previously known or unknown lexical items. That this be ordained from the beginning as a minimum learner target in the context of autonomous learning, even for complete beginners. And I am also proposing that learning material be developed in order to make the acquisition of that skill possible. (Stress and the elementary schwa vowel might form the first stage of such a skill. Shared consonants and vowels the next stage, new vowels the next, and so on.)

54 - (for specific purpose English learners) That at the end of a training module, they should be able to produce, with the added visual support of phonetic transcription, an accurate and comprehensible reading of key words in their specific lexical and morphological field in a time-restricted assessment period. In other words, that the possibility, at least, of a correct pronunciation produced autonomously, independent of their habitual pronunciation in their general everyday communication, be a minimum skill in their own specific lexical and morphological areas of professional, scientific or specific-purpose English. And such a skill will be directed in particular at learners who show, in the precourse assessment test, signs of being auditively weak or of having acquired their pronunciation of English using a predominantly French orthographic pronunciation system.

\subsection{Visual learners' and adult needs}

Perhaps one of the greatest differences between adult and child learners is the fact that the vast majority of adult learners today learn with the aid of a visual language support i.e., through reading. Even in the most communicative of class methods, audio-visual or otherwise, the adult learner will be faced with the English text as a constant visual, presentation and memory support. The adult is already a reader but not in the strict sense of the term in the English language. That is to say, presented with sound symbols which have little or no relation to his or her L1, the adult will often fail to register or perceive that the visual support is actually blinding his or her auditive sense.

56 I have noticed that some profoundly visual learners remain orally almost unintelligible and have serious comprehension difficulties even with standard accent native speakers and even after reaching a very high level of lexical and morphological competence in their written expression. Learning correct pronunciation, even in the English-speaking environment, would appear to be an extremely difficult task to perform for such weak 
auditive French adult learners (those who have poor auditive memories) and strong visual child or adult learners (those who have strong visual memories) and in particular where English is concerned - given the very special orthographic relationship between the two languages.

The visual symbol radio is not much of a visual support for a weak auditive French adult learner in order to read the correct English sound, even after hearing the standard pronunciation several times. A French transcription (such as / réhi!dyehou/) will mean little or nothing to a non-French-speaking native reader of English, but it may help a weak French auditive reader, as it calls upon the visual elements from a previously acquired system and provides some way of memorising a more appropriate pronunciation than the French / rad yo!/ as transcribed in English. ${ }^{1}$

Purely auditively perceived pronunciation learning and teaching is also an extremely difficult task for adults to operate in a much shorter time period than for the child who will have the benefits of a longer developmental learning process, one which is favoured also by the physio-psychological development of the ear and brain. The four or five hours spent in class (according to my own experience with adult learners) learning how to make use of the pronunciation guide will mean years and years of independent pronunciation accuracy being acquired later on, both inside and outside the classroom. And it is surely the job of adult teachers to take into account not just the 20,40 or 60 -hour module of teacher presence, but the number of skills allowing the adult learner to go on developing after acquiring skills which will tend to increase his autonomy and his accuracy, and not his dependence and frustration.

There is little doubt in my mind, again from my experience, that all language learners do want to achieve the greatest pronunciation accuracy possible. Not only, in my opinion, is there a link between improving pronunciation and improved auditive comprehension, but it would appear to be a measure of success that gives learners confidence and even pleasure when speaking. But I have observed that some learners will work far more efficiently and memorise pronunciation much better if given or encouraged to use a visual memory support. Many learners often do not appreciate the problems of transfer of reading skills from one language to another, and attribute pronunciation problems to what they call a "bad ear" or "no ear at all". The problem might better be described as one of a good eye or no visual support system.

Teaching the learner how to make use of the dictionary pronunciation guide, we can of course simply describe, explain to and accompany the learner through the chosen elements of the phonetic alphabet. Or we can seek to provide autonomous or learnerbased elements in the teaching and acquisition of this skill. Or we can mix the two, as required by each individual learner, and depending on the particular item or skill.

The autonomous approach will seek to:

- establish and make use of what the learner already knows in order to be able to call upon that knowledge in the acquisition of the new skill;

- distinguish between elements requiring the greatest teacher support and those which can be learned by the learner alone, and then elaborate a methodology which will rely on either autonomous materials and activities alone, or both teacher-assisted and some experimental or improvised autonomous materials and activities;

- seek to elaborate a time-programme or observe natural rhythms for learning the skill and thereafter create the evaluative means to verify that the skill has indeed been acquired. 

the learner's L1 (French) in making himself familiar with the phonetic pronunciation of French words first. I noticed that learners found it fun when they were asked to select phonetic transcription of French words, at random, from the French side of the dictionary and see if their colleagues could read the list of ten words. They often selected words containing novel elements or those which provided regional differences (pattes, pâtes, calme, château, drôle, rose...) and homonymic spelling contrasts (suit, suis, est, et, aller, allez...). This made the learners aware of his or her own orthographic previously acquired skills, and called on a minimum memorisation of new symbols in order to develop a new skill which will later help in new language acquisition.

sought to focus learners on the shared phonetic consonants and vowel symbols between English and French at the beginning, then focus on new symbols for French sounds, before leaving the realms of French phonetic transcription and entering that of the new symbol/new sound. applied not only to the English language phonetic symbols but even to the French. It became apparent to me that learners who could not perform with new graphic symbols in their own language were going to find it very hard to combine both sound and vision novelty in the second language.

Reading new symbols which provide no sound-production problems was thus a separate activity from known or new symbols providing the problem of acquiring new sounds. Associating those sounds with the graphic symbol - e.g., identifying the two consonant symbols for the $/ \mathrm{TH} /$ poses a different problem for French learners, both visually, auditively and production-wise, than for familiarising the learner with the consonant symbol for / -ING/ or the vowel symbol for schwa which require no lengthy oral practice at all since both sounds are already available in the French language.

I integrated a test for such a skill into general assessment procedures at the end of term, or year or module, telling my students in advance. This was a relatively scientific or mathematical test which allowed the students the pleasure of obtaining full marks whenever the performance was $100 \%$ correct. Most students obtained $75 \%$.

\section{A final comment on my own initial experience}

\subsection{Attempting to exploit what the learner already knows}

In my experience, one of the major problems for learners was actually learning to deal with the phonetic symbols themselves - a purely visual or graphic problem. This was partly psychological, the business of re-learning a new alphabet, and partly pedagogical how to make the learning and acquisition easier than it might appear at the start.

68 I did call upon cassette exercises from Peter Roach's English Phonetics and Phonology, for teaching English-specific vowels, and upon phonetic transcription reading and some exercises from Michel Ginesy's Exercices de phonétique anglaise for more advanced students, but my final basic elementary materials for neophytes to phonetic reading was reduced to Materials:

- A Robert-Collins Dictionary

- 2 photocopies of pages xxvi and xxix of the dictionary per learner 
- 2 photocopies of the International Phonetic Alphabet Chart per learner

- Coloured marker (or a bottle of corrector fluid) per learner.

Chart 2

[Image non convertie]

I found that as a prelude to working on becoming familiar with the phonetic symbols, it was useful to present the adult student with an entirely new visual environment using the very useful International Phonetic Alphabet (Chart 2) given in Peter Roach's English Phonetics and Phonology, the complete alphabet used to visualise and identify the sounds used in human language.

1 The adult learner could quickly observe that this alphabet presented an auditive reality only for the symbols with which they were already familiar - many of the alphabetic consonant and some of the vowel symbols. The visual experience in itself provided a rapid survey of both the complexity and the simplicity of the symbol environment, was the source of interesting learner questions, and, once we had reduced our learning objectives, the task became much simpler and more attractive in appearance.

The chart can be used in a variety of ways, either for complete beginners, or as a discussion object in English with more advanced learners. Naturally the teacher has to be familiar with at least the symbols and sounds available in French and English. But I found that identifying some of the Spanish or Irish sounds, not available in French and English, were a way to reinforce the reduced nature of our teaching and learning task.

3 The French reader will immediately visually recognise many of the sound symbols already available to him on the international phonetic alphabet chart.

If asked to ring or mark off or list those belonging to the French language, he naturally discovers that there are many other sounds used in human language which appear on the chart and which are not used in his own language.

To check that he has identified all the sounds available within the French language, he can be asked to compare his list with the complete list provided in the Robert-Collins Dictionary (p. xxvi), entitled Phonetic Transcription of French. Obviously, the task of finding the new symbols for the sounds, which hitherto he has identified using the French orthographic system, will require that those new symbols be clearly separated in his mind from those symbols (such as $p, b, t$, d, etc.) with which he will already be familiar. The task will be to separate any automatic auditive associations which are likely to cause confusion e.g. $\mathrm{s}, \mathrm{z}$, etc.

In my experience, it is easier to start with the consonant chart first before going onto the vowels. Once the concept has been clearly established in the learner's mind that each graphic symbol equals one precise sound in the range of consonants, it will be much easier to go on to the complex visual-auditive task of examining the vowels.

Using the second photocopy with marker or correction fluid, it can be the learner's task to filter out the irrelevant elements (those previously known) and bring to the fore the new elements to be learned in both French and English. This of course can be already prepared in advance for the learner by the teacher if time does not permit an autonomous discovery and filtering out by the individual learner or learner groups. Either way, the lists on pages xxvi and xxix can be equally reduced to their essential 
learning elements by filtering tasks targeting different learner observations. Here are a few examples:

- By filtering the French transcription list on page xxvi - removing the symbols and sounds which do not exist in English, the learner may learn their redundant context when reading in English

- By filtering the English transcription list on page xxix - removing the sounds in English which already exist in French, the learner may be able to read words in phonetic transcription in both languages without facing the difficulties of any new sounds

- By separating the 5 new (phonetic) symbols representing previously known consonant sounds from the 6 old (alphabetic) symbols representing known but differently associated consonant or semi-vowel sounds, the learner can concentrate on the purely graphic differences which indeed are only a matter of regular practice.

- By separating old (alphabetic) symbols representing unknown sounds from new (phonetic) symbols representing unknown sounds, the teacher will thus be called upon to articulate during teaching time only: Unknown sounds for previously known symbols, and unknown sounds for previously unknown symbols.

The final filtered consonant phonetic chart will look something like this, for example (see Appendix chart 3) and finally filtered phonetic transcription guides might look something like this (see Appendix chart 4).

A tidier and neater version, given phonetic software, could provide some sort of first step towards creating an auto-corrective tool for distance or fully autonomous learners.

The 21 graphic relation skills need to be learned over a little bit of time at the start and they can be acquired in relative autonomy by the learner in an inductive and deconstructive manner, using the learner's previous knowledge.

It is quite unnecessary, in my opinion, to call upon the English language or English orthographic system at this stage which may complicate the target skills. And it is an oddity in my opinion that, given the simplicity of this learning task, dictionaries tend to complicate the matter by providing redundant information on a phonemic chart that tells a French or English reader how to pronounce the letter ' $p$ ' or other known letters in tediously complete fashion, and provide no exercises to help the autonomous starting learner. In some ways, the presentation of the phonetic transcription guide is counterproductively redundant. Alphabetical order in the dictionary is no support for learning a phonetic symbol context and the alphabet of consonants provided in the transcription guide hides the wood for the trees. Indeed, the learner may fail to see the:

- 3 essential consonant differences,

- the 6 essential vowel differences and

- the 2 essential suprasegmental differences

82 All in all, only $\mathbf{1 1}$ basic elements requiring careful attention. But surely in this age, with an audio or even better video-cassette with English-specific and French-specific elements clearly identified and exercised.

Not only that, but the dictionary uses English phonemic key words to teach a French learner new phonetic sounds in English, and French words to teach an English learner new French phonetic sounds! If one can already read the phonemic guide correctly, what is the point of learning how to read it? ${ }^{2}$ 


\subsection{Identifying the auditive and visual novelty}

calling only on French sounds and symbols, or shared French and English sounds and symbols, various games could be exploited to practice exercising the skill, using scrabble phonetics, or phonetic cards, or simply by asking learners to identify whether the word is a French or English word by reading a phonetic transcription list, either drawn up by the teacher or prepared outside of class by learners for later pair work.

soon as the French reader/filterer had become completely familiar with the elements shared between the two languages, and with the use of new graphic symbols for previously acquired sounds, they could better focus on the $\mathbf{1 1}$ consonant, $\mathbf{6}$ vowel and $\mathbf{2}$ (or 3) suprasegmental phonetic symbols in English with which they were not familiar for different reasons. Where the $\mathbf{1 1}$ consonants were concerned, $\mathbf{5}$ do not belong to their previously acquired visual alphabetic system, $\mathbf{6}(\mathbf{r}, \mathbf{s}, \mathbf{z}, \mathbf{x}, \mathbf{h}$, and $\mathbf{j}$ ) have a slightly individual relationship with the French learner's auditive habits $(/ \mathrm{r} /$ does not equal /R/, /s/ is always /s/ and never / $\mathrm{z} /$ etc.) - but really only 9 of these symbols present the need for more attention and a little serious graphic initiation. And obviously only 3 of the consonants require articulatory attention for teacher pronunciation practice.

same process was to be used for the vowels, which of course show greater differences. Shared vowel sounds and symbols needed only auditive/visual association and careful graphic attention without presenting any articulatory problems. Englishspecific vowels were naturally to require much greater attention, both visually and orally.

One feature I noticed is that while many French readers had hitherto tended either to call on previously acquired French vowel and consonant sounds (either those which have close articulatory characteristics, or close pairs) to effect a reading of English-specific vowels and consonants in a list of selected English words or sentences, once they had spent between 4 or 5 hours working with the phonetic transcription support, they became far more careful and attentive in their use of the dictionary. They spent much time repeating in front of the class the same word again and again without any organised pronunciation practice. This also meant that learners could work on pronunciation practice outside of class time, leaving the teacher-participation period free for communicative and grammar work.

88 I noticed however that some students continue to ignore suprasegmental long vowel and stress indications (/i/ for /i:/ etc.) even while reading the phonetic transcription, or they cling to previously acquired pronunciation using the orthographic spelling, even when the phonetic support is given alongside the usual English spelling. I noticed too that very often these were students with good general pronunciation - those who generally showed themselves to have good auditive memories. It may be that because of their strong auditive habits in picking up the language, they resent or dislike having to be disciplined by a visual support.

Trying to restrict the time spent in teaching this skill also led me to the conclusion that while in certain articulatory problem consonants such as the English /r/, this does not really present any serious problem of intelligibility later on, given that the uvular French / $R /$ is almost a prestige variant in the English language and the retroflex / $/$ / has so many varieties from region to region in the English-speaking world. The practice of not reading the /h/ correctly, or using /s/ or /z/ consonants for the two -TH sounds, or using French 
vowel sounds or approximations for the English-specific vowels could obviously provide serious intelligibility problems later on, and thus did seem to point towards more overt pronunciation practice and teaching than any of the other vowels.

In my own brief exploration of this area over a naturally limited number of hours devoted to teaching these vowels, I have found that recognition problems, articulatory problems and ultimately comprehension problems can sometimes be reduced to a minimum by focusing attention on close pairs between French and English.

This may involve recognition of which belongs to which language, or which is a known word and which is not. My own knowledge in this area is too limited however and my experience here has been too brief to make any worthwhile propositions for the moment. No doubt it will require many years yet and the assistance of expert phoneticians before making much progress.

\section{One problem using the dictionary}

While the dictionary provides exhaustive material for reading known and unknown words using the phonetic support, unfortunately it does so not in any phonetic order but in an absurdly irrelevant alphabetical order. And where English pronunciation methods are concerned, they rarely use phonetic support transcription and are often not directed at specifically French-reading learners. What a joy it would be to have a nonalphabetical specific phonetic dictionary (in order of phonetic opening, or of phonetic difficulty) to help specifically French readers develop reading specific phonetic skills! Perhaps the computer can help here some day.

\subsection{Setting targets for assessment of autonomy and skill acquisition as well as language acquisition}

Once the second language-learner appreciates the freedom provided by the acquisition of such a pronunciation reading skill in providing a self-corrective means of checking and improving his pronunciation of English words, and has learned to distrust the English orthographic system as a relatively unreliable one for the uninitiated French-speaking reader, he or she can be encouraged to make use of this support in various stages. In my own classes, I integrated the assessment of phonetic support reading into final module assessment, telling the students in advance that it was a minimum skill to have acquired over a period of 5 hours spread out over a year. After 10 half-hour teaching periods and about 10 hours of individual autonomous work devoted to acquiring the skill with the dictionary, and a specific-purpose lexical reading test at the end, most students seemed to have found the skill useful, and actually started to integrate it at least into their lexical consultation of the dictionary.

It is difficult to know yet to what degree they will maker use of such a skill in their ongoing language-learning as adults, but it is my hope that they at least will have been given the opportunity to continue to autonomously improve their pronunciation long after they have forgotten my classes. 
BIBLIOGRAPHY

Ginesy, Michel. 1989. Exercices de phonétique anglaise. Paris: Nathan.

Montessori, Maria. 1958a. Pédagogie scientifique. Paris: Desclée de Brouwer.

Montessori, Maria. 1958b. De l'enfant à l'adolescent. Paris: Desclée de Brouwer.

Montessori, Maria. 1959. L'esprit absorbant de l'enfant. Paris: Desclée de Brouwer.

Montessori, Maria. 1973. The Advanced Montessori Method, vols. 1 \& 2. New York: Schocken Books.

Roach, Peter. 1991. English Phonetics and Phonology: A Practical Course, new edition. Cambridge: Cambridge University Press.

Robert-Collins Dictionary. 1991. Français-anglais - anglais-français. Paris: Le Robert.

\section{APPENDIXES}

\section{Appendix: Chart 3}

[Image non convertie]

Appendix: Chart 4

[Image non convertie]

\section{NOTES}

1. As I am not yet equipped with software allowing me to print phonetic symbols into the computer, my use of learner transcription here is not as policy, but just a useful stop-gap support - as in class where I have found it can be immediately accessible to the learner and serve as a pre-phonetic pronunciation reading stage.

2. It is also interesting to note that the same phonetic symbol /e/ is used in the Robert-Collins dictionary for the French word blé and the English word "less" - surely an element of confusion for both French and English speakers. Should we pronounce both words with the same sound? Hardly. Why then do we use the same symbol for two slightly different sounds?

\section{ABSTRACTS}

Using the work of Maria Montessori as a source of reflection in trying to define what authentic adult autonomy might be and what the redefined role of the teacher needs to be with regard to the autonomous learning process, I have attempted to make use of a few of the elements from 
her autonomous child-learning principles, in the course of my teaching year following my DEA studies. This I summarise and discuss, in particular, my introduction of the dictionary and use of phonetic reading skills in class, intended to give my students greater autonomy.

En essayant de définir quelques principes dune «autonomie authentique » chez l'apprenant adulte, et de redéfinir le rôle de l'enseignant dans le processus d'un apprentissage autonome, je fais appel à l'œuvre de Maria Montessori. Je tente d'en extraire certains éléments utiles de ses principes d'apprentissage autonome chez l'enfant, et je résume mon expérience personnelle en tant qu'enseignant, au cours d'une année après le DEA d'anglais de spécialité, pendant laquelle j'ai tenté d'introduire l'utilisation du dictionnaire et du support phonétique pour rendre mes étudiants plus autonomes.

\section{INDEX}

Mots-clés: autonomie, Montessori, prononciation, phonétique

Keywords: autonomy, phonetics, pronunciation, reading

\section{AUTHOR}

\section{MARTIN WALTON}

IUT de Bayonne. martin.walton@iutbayonne.univ-pau.fr 